Earthquake Resistant Engineering Structures XIII PII-3

\title{
FRAGILITY ASSESSMENT OF THE INTER-STORY POUNDING RISK BETWEEN ADJACENT REINFORCED CONCRETE STRUCTURES BASED ON PROBABILISTIC SEISMIC DEMAND MODELS
}

\author{
MARIA G. FLENGA \& MARIA J. FAVVATA \\ Department of Civil Engineering, University of Patras, Greece
}

\begin{abstract}
The aim of this study is the probabilistic evaluation of the seismic performance of a multistory reinforced concrete $(\mathrm{RC})$ frame structure due to the inter-story pounding effect. The assessment is performed through fragility curves at different performance levels. For this purpose, different probabilistic seismic demand models (PSDMs) are developed based on the real seismic response of the $\mathrm{RC}$ structure as a function of the spectral acceleration (Sa). In this direction, the inter-story (floor-tocolumn) pounding between an 8 -story RC frame structure and a 3-story rigid barrier (very stiff structure) is examined. Three different initial gap distances $\left(\mathrm{d}_{\mathrm{g}}\right)$ between the adjacent structures are considered. The seismic fragility assessment of the 8-story RC structure without the inter-story pounding effect is also incorporated. Results indicate that the local performances of the columns of the 8-story RC structure are crucial demand parameters for the probabilistic assessment of the inter-story pounding risk. The fragility curves are shifted to lower values of Sa due to the pounding effect in comparison to the corresponding cases without pounding, while the probability of pounding between the examined structures is increased as the separation gap distance $d_{g}$ decreases. Nevertheless, the more exigent the performance level is the fragility curves move towards greater values of earthquake intensity.

Keywords: reinforced concrete frame, inter-story pounding, probabilistic assessment, fragility curves, performance levels, Eurocode 8, nonlinear dynamic analyses, PSDMs.
\end{abstract}

\section{INTRODUCTION}

In modern seismic engineering, over the last two decades, several researches have been undertaken to address the seismic performance of buildings through probabilistic procedures providing solutions and a better insight into seismic risk aspects of structures.

An important parameter for the evaluation of the seismic performance of structures is the pounding phenomenon between adjacent buildings that have been constructed in contact or with insufficient gap distance. Although interaction effects are independent from the initial structural design provisions it has been proved to be crucial for the integrity of the structural stability. Thus, the problem of the structural pounding between adjacent buildings has received substantial attention over the last two to three decades [1]-[10] and numerous results based on the deterministic assessment of the pounding effect on the seismic performance of real multistory structures have been reported in the literature [7]-[10]. However, review of the literature indicates that the probabilistic evaluation of the pounding problem is still in an early state of knowledge. So far, single-degree of freedom (SDOF) and/or multi-degree of freedom (MDOF) linear elastic systems, as well SDOF nonlinear systems have been used. In most of the cases, the peak relative displacement between the adjacent structures has been examined as key parameter of the pounding risk, while only the case of floor-to-floor pounding type has been considered [11]-[21]. Lack of relation attempts between the seismic performances of a real structure with the probabilistic assessment of the pounding effect still exists and more limitations are identified. In existing probabilistic methodologies, the local 
inelastic demands of the critical structural members have not been incorporated. The necessity for the verification of the local demand parameter is pointed out since it has been proved that this parameter is the most crucial issue on the seismic performance of structures due to pounding effect [9].

Nevertheless, in 2020, Flegga and Favvata [22], evaluated the floor-to-floor structural pounding effect on the seismic performance of an 8-story RC frame structure at different performance levels based on probabilistic assessment methods. Initial results that are based on the local demands of the structural members have also been presented. The probabilistic evaluation of the pounding effect is performed through fragility curves in terms of global and local engineering demand parameters (EDPs) as a function of peak ground acceleration (PGA) and Sa. Finally, in 2021, Kazemi et al. [23], studied the floor-to-floor structural pounding between equally heighted 3, 5 and 9 story RC and steel moment resisting frames (MRFs) at different seismic performance levels. The seismic limit states' capacities of the structures are defined through the median incremental dynamic analysis (IDA) curve using the global engineering demand parameter of maximum interstory drift. For the evaluation of the pounding effect, fragility curves based on IDA have also been developed in terms of maximum interstory drift as a function of the Sa.

Based on the above discussion, in this study a probabilistic assessment of the seismic inter-story (floor-to-column) pounding risk is attempted taking into account both global and local seismic responses of the examined RC structure.

\section{EXAMINED INTER-STORY POUNDING CASE}

The examined inter-story pounding case is an interaction case between an 8-story RC frame and a 3-story rigid barrier (very stiff structure). The story levels of the adjacent structures are not equal, so the slab of the shorter and stiffer structure hits the external column of the taller building. The top level of the potential contact point is located at the $1 / 3$ of the height of the 4th floor level of the 8-story RC frame. The examined pounding case is shown in Fig. 1. Based on Eurocode's 8 provisions, a minimum gap distance equal to $9.0 \mathrm{~cm}$ between the 8 story $\mathrm{RC}$ frame structure and the 3-story rigid barrier is required to prevent pounding at the 4 th floor level of the RC frame. Nevertheless, for the needs of this study, three different initial gap distances $\left(\mathrm{d}_{\mathrm{g}}\right)$ are considered, namely $\mathrm{d}_{\mathrm{g}}=0.0 \mathrm{~cm}$ (structures in contact from the beginning), $d_{g}=4.5 \mathrm{~cm}$ and $d_{g}=9.0 \mathrm{~cm}$ (Eurocode's requirement). The seismic performance of the 8-story RC structure without the pounding effect is also included for comparison reasons.

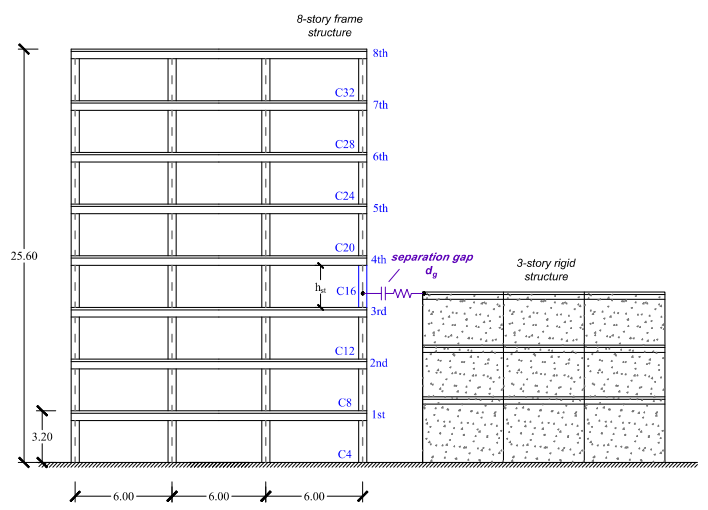

Figure 1: Examined 8-story RC frame structure. 


\section{DESIGN AND MODELLING ASSUMPTIONS}

The 8-story RC frame structure was designed according to Eurocodes 2 and 8, meeting the Ductility Capacity Medium (DCM) criteria of the codes. The seismic behavior factor for the frame was $\mathrm{q}=3.75$. The mass was taken equal to $\mathrm{M}=(\mathrm{G}+0.3 \mathrm{Q}) / \mathrm{g}$ (where $\mathrm{G}$ gravity loads and $\mathrm{Q}$ live loads) and the design base shear force was equal to $\mathrm{V}=(0.3 \mathrm{~g} / \mathrm{q}) \mathrm{M}$. The computer program package Drain-2dx is used. Beams of the structure have been simulated through a common lumped plasticity model and columns by a special purpose element of "distributed plasticity" type accounting for the spread of inelastic behavior both over the cross-sections and along the deformable region of the member length. Collisions are simulated using contact elements that become active when the corresponding nodes come into contact. The response of the contact element is described by: a) the negative direction of the $\mathrm{X}$-axis that represents the condition that the buildings move away from each other and $b$ ) the positive direction of the $\mathrm{X}$-axis that simulates the actual behavior of the structures in case there is a small gap distance $\left(\mathrm{d}_{\mathrm{g}}\right)$ between them. More details regarding the structural design characteristics and the modelling assumptions of the 8-story RC frame can be found in Favvata [9].

\section{KEY ISSUES FOR DEVELOPING THE PSDMS}

\subsection{Examined EDPs-IMs}

A probabilistic seismic demand model (PSDM) is a mathematical relation between the structural response and the earthquake intensity measure (IM). The structural response is described through engineer demand parameters (EDPs) representing the global or the local responses of a structural system while the intensity measures (IMs) refer to ground motion characteristics that may be structural independent (e.g. PGA) or structural dependent (e.g. Sa). In this study, the necessary EDPs samples are accomplished as a function of the Sa and the probabilistic seismic demand models are developed considering the following EDPs: (a) maximum displacement $\left(\delta_{\max }\right)$ at the top level of contact point with the 3-story rigid structure, (b) maximum interstory drift $\left(\mathrm{IDR}_{\max }\right)$, (c) maximum top drift $\left(\mathrm{TDR}_{\max }\right)$, (d) maximum curvature ductility demands $\mu_{\varphi, \max }$ and (e) maximum shear demands $V_{\max }$ of the external columns at the pounding side of the frame.

\subsection{Probabilistic seismic demand models}

In order to develop a PSDM, EDP|IM pairs should be generated through nonlinear dynamic analysis. In this direction, IDA method [24] has been used to define the seismic demands of the 8-story RC structure due to the pounding effect. Both components of seven different seismic excitations (totally 14 records) extracted from the PEER's database are used with Sa to be scaled in the range of $0.005 \mathrm{~g}$ to $1.4 \mathrm{~g}$. Thus, a total number of 616 inelastic dynamic analyses have been performed. More details regarding the characteristic of the seismic excitations can be found in Flegga and Favvata [22]. Statistical process of EDP|IM pairs synthesizes the PSDM. The mathematical representation of median structural demand response EDP and the IM can be approximated by a two parameters power law model [25], [26]:

$$
\widehat{E D P} \mid I M=a I M^{b} .
$$

The coefficients $\alpha$ and $b$ are calculated through linear regression analysis of logarithm of IM and EDP, so the eqn (1) is transformed to the following expression: 


$$
\ln \widehat{E D P}|I M=b \ln I M+\ln a+\varepsilon| I M,
$$

where $\varepsilon \mid \mathrm{IM}$ is the random error with mean zero and variance $\sigma^{2}$.

The structural response demand is assumed to follow lognormal distribution [25] with logarithm standard deviation $\beta_{\mathrm{EDP} \mid \mathrm{IM}}$ which is calculated by the following equation:

$$
\beta_{E D P \mid I M}=\sqrt{\frac{\sum_{i=1}^{n}\left(\ln E D P_{i}|I M-\ln \widehat{E D P}| I M\right)^{2}}{n-2}} .
$$

The mathematical representation of the PSDM leads to a closed form solution that permits the definition of the fragility curves. Each fragility curve describes, the probability an EDP to exceed the capacity $\widehat{C}$ for a given IM and can be calculated as:

$$
P[E D P|I M \geq C| I M]=\Phi\left(\frac{\ln \widehat{E D P} \mid I M-\ln \hat{C}}{\beta_{E D P \mid I M}}\right) .
$$

$\Phi($.$) denotes the standard normal cumulative function, \widehat{C}$ the median value of the capacity and $\beta_{\text {EDPIIM }}$ the logarithm standard deviation (eqn. (3)).

Nevertheless, linear representation of PSDM is not always accurate to describe the structural response for the entire range of IM [27]. The adoption of a bilinear regression model especially for local EDPs seems to be more valid to capture the nonlinear behaviour of the structural members. The bilinear regression model can be described as:

$$
\ln \widehat{E D P}\left|I M=\left(a_{1}+b_{1} \ln I M\right)\left(1-H_{1}\right)+\left[\ln E D P \mid I M^{*}+b_{2}\left(\ln I M-\ln I M^{*}\right)\right] H_{1}+\varepsilon\right| I M .
$$

Coefficients $\alpha_{1}, b_{1}$ and $b_{2}$ are defined through linear regression analysis. $\mathrm{H}_{1}$ is a dummy variable is equal to $\mathrm{H}_{1}=0$ for $\mathrm{IM} \leq \mathrm{IM}^{*}$ and $\mathrm{H}_{1}=1$ for $\mathrm{IM}>\mathrm{IM}^{*}$. The parameter $\mathrm{IM}^{*}$ repressents the intersection of the two linear branches.

In this study, as it can be observed in Fig. 2, the global EDPs of IDR $\max _{\max }$ and $\mathrm{TDR}_{\max }$ seem to fit better the linear regression model. On the other hand the local demand of the external column $\mathrm{C} 16$ that suffers the impact seems to be expressed more accurate through a bilinear model. In Figs 3 and 4 the PSDMs in terms of $\mu_{\varphi, \max } \mid \mathrm{Sa}$ and $\mathrm{V}_{\max } \mid \mathrm{Sa}$ using linear and bilinear regression model are presented for all the examined pounding cases.

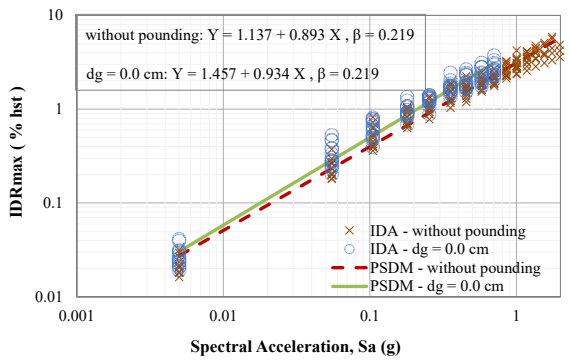

(a)

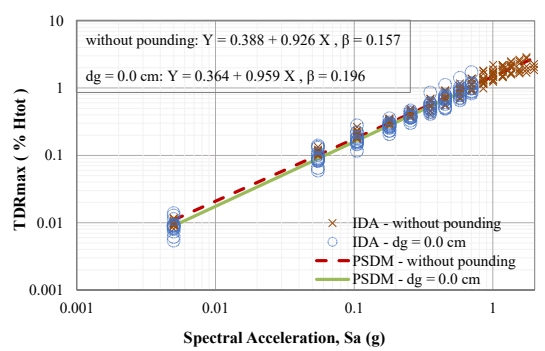

(b)

Figure 2: Linear PSDMs in log-log space for the global EDPs of (a) maximum interstory drift $\mathrm{IDR}_{\max }$; and (b) maximum top drift $\mathrm{TDR}_{\max }$, as a function of $\mathrm{Sa}$. 


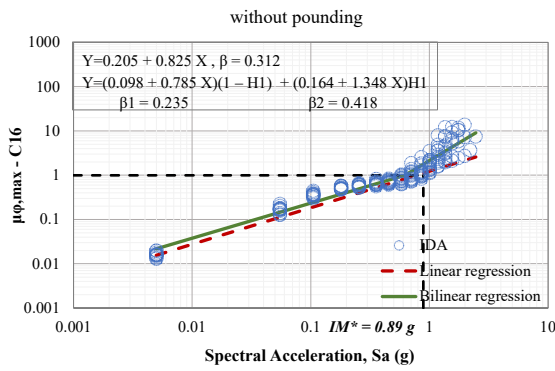

(a)

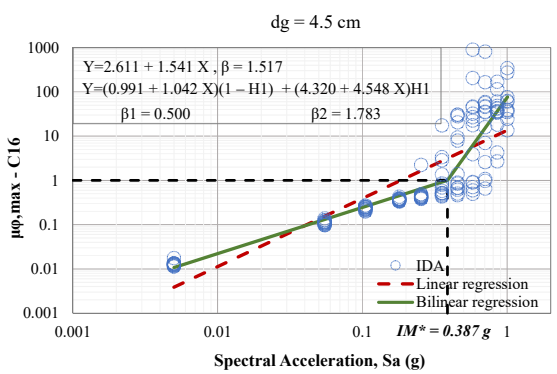

(c)

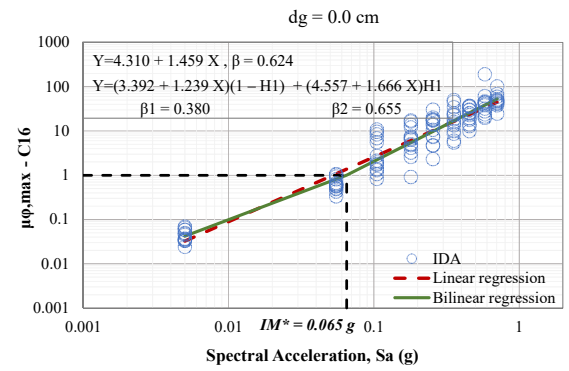

(b)

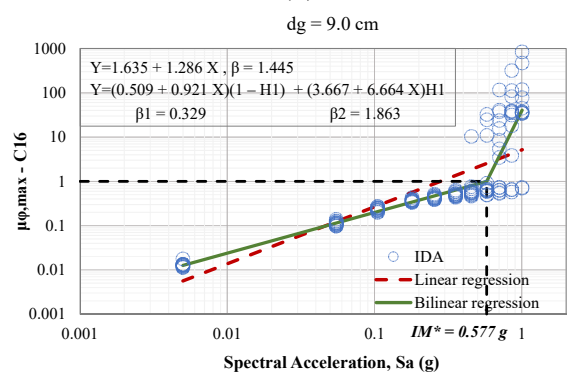

(d)

Figure 3: Linear and bilinear PSDMs in terms of $\mu_{\varphi, \max } \mid \mathrm{Sa}$ (in log-log space). Examined cases. (a) Without pounding; (b) $\mathrm{d}_{\mathrm{g}}=0.0 \mathrm{~cm}$; (c) $\mathrm{d}_{\mathrm{g}}=4.5 \mathrm{~cm}$; and (d) $\mathrm{d}_{\mathrm{g}}=9.0 \mathrm{~cm}$.

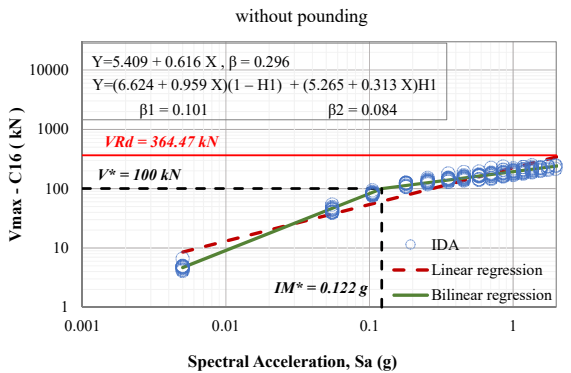

(a)

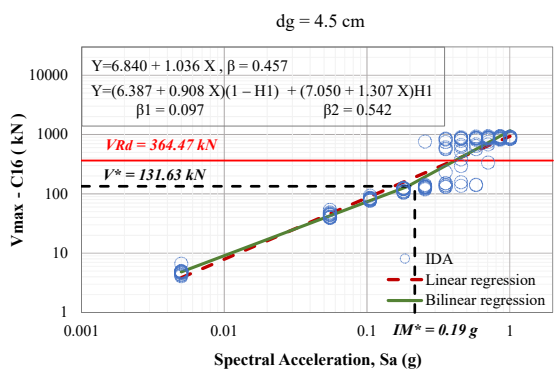

(c)

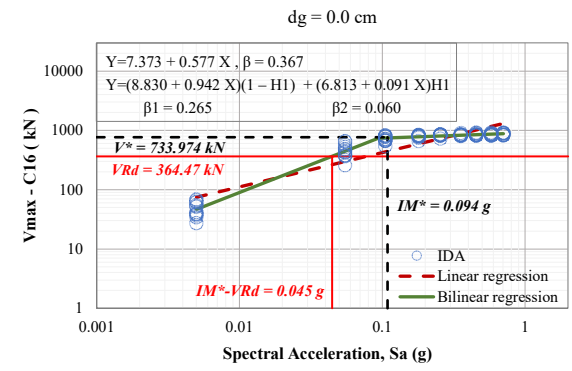

(b)

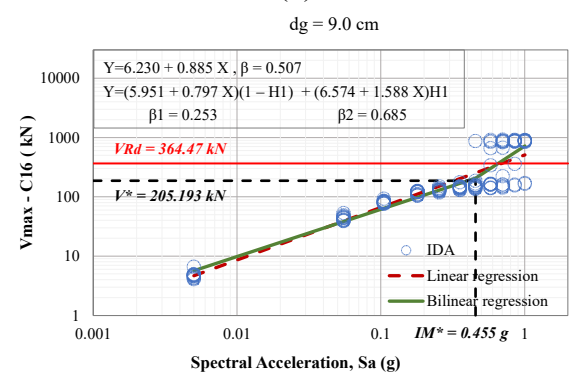

(d)

Figure 4: Linear and bilinear PSDMs in terms of $\mathrm{V}_{\max } \mid \mathrm{Sa}$ (in $\log -\log$ space). Examined cases. (a) Without pounding; (b) $\mathrm{d}_{\mathrm{g}}=0.0 \mathrm{~cm}$; (c) $\mathrm{d}_{\mathrm{g}}=4.5 \mathrm{~cm}$; and (d) $\mathrm{d}_{\mathrm{g}}=9.0 \mathrm{~cm}$. 


\subsection{Examined performance levels - PLs}

The probabilistic evaluation of the pounding effect is performed through fragility curves in terms of EDP $\mid \mathrm{Sa}$. The fragility curves of this study are developed based on different structural global and local performance levels. In this direction, the next four global performance levels are chosen to be examined for the $\mathrm{IDR}_{\max }$ and $\mathrm{TDR}_{\max }$ demand parameters [29]: (i) Immediate Occupancy (IO) that corresponds to a maximum interstory drift equal to $1 \%$ of the story height $\left(\mathrm{h}_{\mathrm{st}}\right)$, (ii) Life Safety (LS) that corresponds to a maximum interstory drift equal to $1.5 \%$ of the story height $\left(\mathrm{h}_{\mathrm{st}}\right)$, (iii) Collapse Prevention (CP) that corresponds to a maximum interstory drift equal to $2.5 \%$ of the story height $\left(\mathrm{h}_{\mathrm{st}}\right)$ and (iv) top drift equal to $1 \%$ of the total height of the structure $\left(\mathrm{H}_{\mathrm{tot}}\right)$. The local curvature ductility capacities $\left(\mu_{\varphi-\mathrm{PL}}\right)$ of columns have been estimated for Damage Limitation (DL), Significant Damage (SD) and Near Collapse (NC) performance levels based on Eurocode 8-part3. Finally, the local shear performance (maximum shear force $V_{\max }$ ) of columns against pounding has been verified considering the design shear strength $\left(\mathrm{V}_{\mathrm{Rd}}\right)$.

\section{RESULTS}

In Fig. 5, the probability a pre-defined displacement to exceed at the top level of the contact point of the examined adjacent structures, is evaluated. As pre-defined displacement limit is considered the initial gap distance $\mathrm{d}_{\mathrm{g}}$ between the adjacent structures. It can be observed that the 8-story $\mathrm{RC}$ frame is more vulnerable to pounding with the adjacent shorter and stiffer structure as smaller the initial separation gap distance between them is. For a probability of pounding equal to $60 \%$, an earthquake intensity of $0.35 \mathrm{~g}$ is critical when $\mathrm{d}_{\mathrm{g}}=4.5 \mathrm{~cm}$, while in the case of $\mathrm{d}_{\mathrm{g}}=9.0 \mathrm{~cm}$ the critical value of IM is $0.75 \mathrm{~g}$. A different approach provides that for an earthquake intensity of $\mathrm{Sa}=0.3 \mathrm{~g}$ the probability of pounding between the examined structures is about $43 \%$ for $\mathrm{d}_{\mathrm{g}}=4.5 \mathrm{~cm}$ while in case of $\mathrm{d}_{\mathrm{g}}=9.0 \mathrm{~cm}$ this probability is less than $10 \%$.

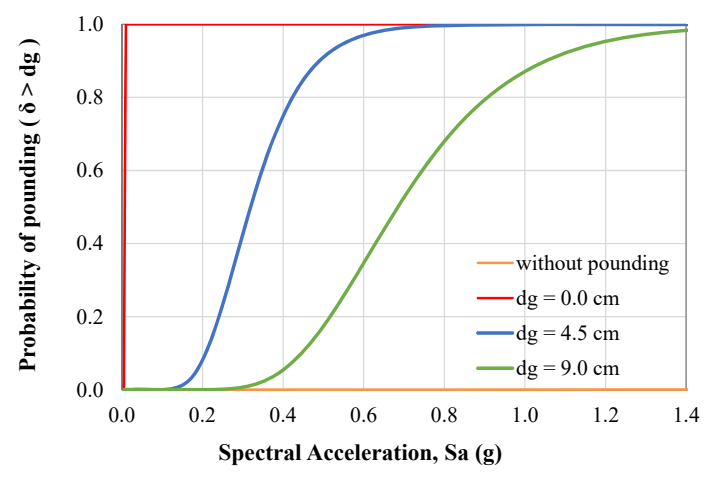

Figure 5: Probability of inter-story pounding between the 8-story RC frame and the 3-story rigid barrier structure, when $\mathrm{d}_{\mathrm{g}}=0.0 \mathrm{~cm}, \mathrm{~d}_{\mathrm{g}}=4.5 \mathrm{~cm}$, and $\mathrm{d}_{\mathrm{g}}=9.0 \mathrm{~cm}$.

In Figs 6 and 7, the influence of the inter-story pounding effect on the fragility assessment of the 8-story RC frame in terms of $\mathrm{IDR}_{\max } \mid \mathrm{Sa}$, and $\mathrm{TDR}_{\max } \mid \mathrm{Sa}$ is presented and discussed. Fig. 6 shows that in the case of earthquake-induced pounding, the 8-story RC frame has exhibited the same probability of exceeding a particular performance level (PL) of IDRmax 


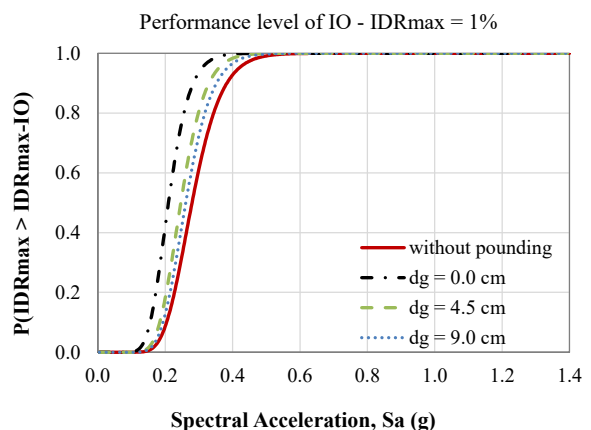

(a)

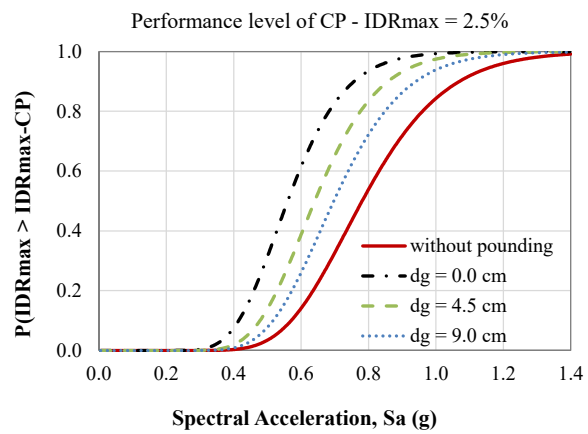

(c)

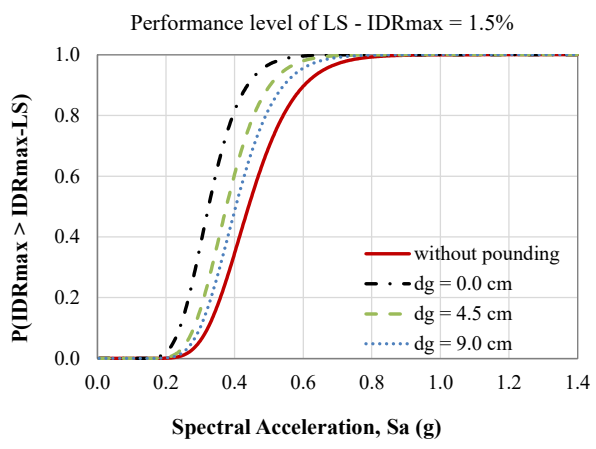

(b)

\begin{tabular}{|c|c|c|c|c|c|}
\hline \multirow{2}{*}{$\begin{array}{c}\mathrm{Sa} \\
{[\mathrm{g}]}\end{array}$} & \multicolumn{5}{|c|}{$\mathrm{P}\left(\mathrm{IDR}_{\max }>\mathrm{IDR}_{\max }-\mathrm{PL}\right)$} \\
\cline { 2 - 6 } & $\mathrm{PL}$ & $\begin{array}{c}\text { Without } \\
\text { pounding }\end{array}$ & $\begin{array}{c}\mathrm{d}_{\mathrm{g}}=0.0 \\
{[\mathrm{~cm}]}\end{array}$ & $\begin{array}{c}\mathrm{d}_{\mathrm{g}}=4.5 \\
{[\mathrm{~cm}]}\end{array}$ & $\begin{array}{c}\mathrm{dg}=9.0 \\
{[\mathrm{~cm}]}\end{array}$ \\
\hline \multirow{3}{*}{0.3} & IO & $61 \%$ & $93 \%$ & $81 \%$ & $72 \%$ \\
\cline { 2 - 6 } & $\mathrm{LS}$ & $5 \%$ & $37 \%$ & $16 \%$ & $10 \%$ \\
\cline { 2 - 6 } & $\mathrm{CP}$ & $0 \%$ & $4 \%$ & $0 \%$ & $0 \%$ \\
\hline 0.6 & $\mathrm{CP}$ & \multicolumn{6}{|c|}{ PL: performance level } & $62 \%$ & $39 \%$ & $26 \%$ \\
\hline \multicolumn{7}{|c|}{} \\
\hline
\end{tabular}

(d)

Figure 6: Fragility assessment of the 8-story RC frame against the inter-story pounding risk, in terms of IDRmax $\mid \mathrm{Sa}$ at different performance levels, when $\mathrm{dg}=0.0 \mathrm{~cm}$, $\mathrm{dg}=4.5 \mathrm{~cm}$, and $\mathrm{dg}=9.0 \mathrm{~cm}$.

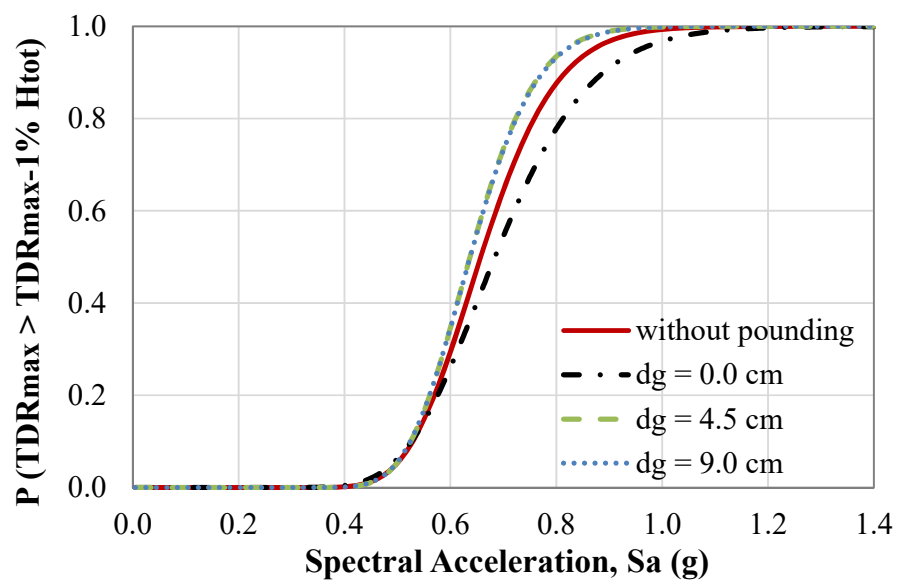

Figure 7: Fragility assessment of the 8-story RC frame against the inter-story pounding risk, in terms of $\mathrm{TDR}_{\max } \mid \mathrm{Sa}$, when $\mathrm{d}_{\mathrm{g}}=0.0 \mathrm{~cm}, \mathrm{~d}_{\mathrm{g}}=4.5 \mathrm{~cm}$, and $\mathrm{d}_{\mathrm{g}}=9.0 \mathrm{~cm}$. 
(\%hst) at a lower value of $\mathrm{Sa}$ in comparison to the case without the pounding effect. The probability for the 8-story RC frame to exceed a specific PL of IDR $\mathrm{max}_{\max }$ at the same Sa value is increased due to the pounding effect as the initial gap distance between the adjacent structure is decreased. Indicative results for $\mathrm{Sa}=0.3 \mathrm{~g}$ and $\mathrm{Sa}=0.6 \mathrm{~g}$ are shown in Fig. $6 \mathrm{~d}$. On the other hand, meaningless seems to be the influence of the pounding effect on the fragility curves of the 8-story $\mathrm{RC}$ frame in terms of $\mathrm{TDR}_{\max } \mid \mathrm{Sa}$ (Fig. 7).

In Fig. 8, results about the influence of the inter-story pounding effect on the fragility curves of the 8-story RC frame in terms of $\mu_{\varphi, \max } \mid \mathrm{Sa}$ at different performance levels are presented.

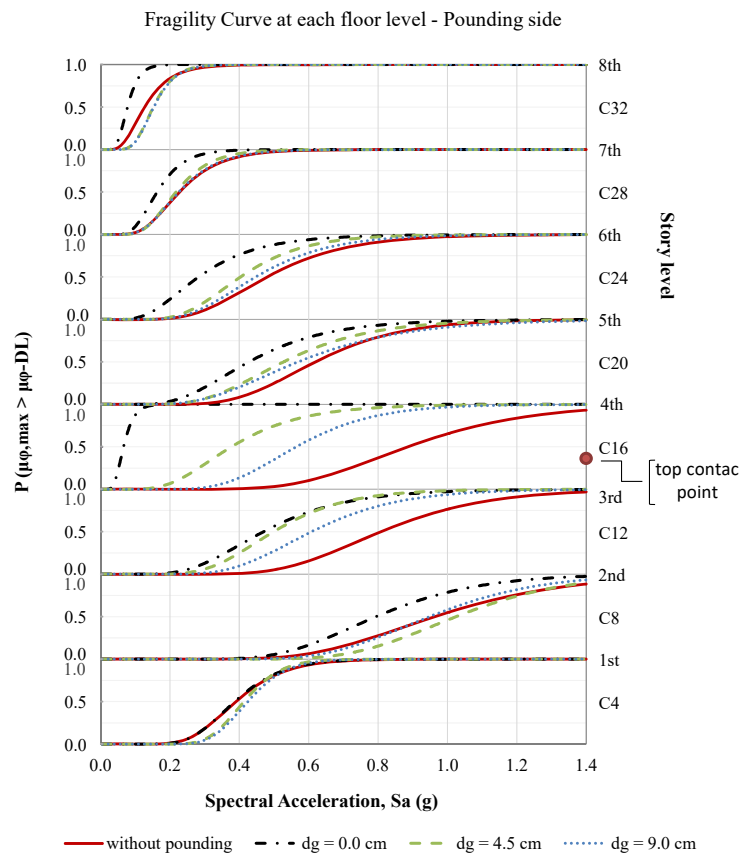

(a)

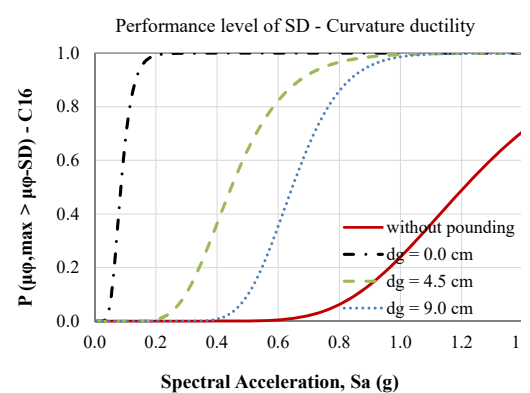

(b)

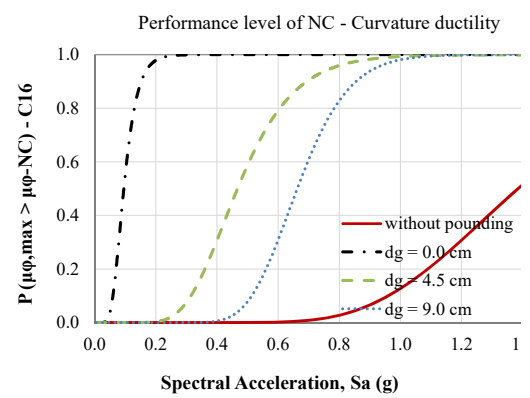

(c)

Figure 8: Fragility assessment of the external columns (at the pounding side) of the 8-story $\mathrm{RC}$ frame against the inter-story pounding risk, in terms of $\mu_{\varphi, \max } \mid \mathrm{Sa}$, at different performance levels, when $\mathrm{d}_{\mathrm{g}}=0.0 \mathrm{~cm}, \mathrm{~d}_{\mathrm{g}}=4.5 \mathrm{~cm}$, and $\mathrm{d}_{\mathrm{g}}=9.0 \mathrm{~cm}$.

Based on these results it can be observed that critical due to the pounding effect is the local response of the external column $\mathrm{C} 16$. So, for example, when an earthquake intensity equal to $0.4 \mathrm{~g}$ is assumed, the probability the external column $\mathrm{C} 16$ to exceed the curvature capacity at the performance level of DL is $13 \%$ when $\mathrm{d}_{\mathrm{g}}=9.0 \mathrm{~cm}$. This probability is increased to a value of $55 \%$ when the initial gap distance between the adjacent structures is equal to $4.5 \mathrm{~cm}$ and to a value of $100 \%$ for $\mathrm{d}_{\mathrm{g}}=0.0 \mathrm{~cm}$. In all the examined cases of "without pounding effect" the column's response is elastic one (probability equal to zero) for $\mathrm{Sa}=0.4 \mathrm{~g}$. Also, it can be observed that in all the examined cases when the separation gap distance between the structures is decreased the fragility curves shift towards a lower value of Sa. In the case where the adjacent structures are in contact from the beginning $\left(\mathrm{d}_{\mathrm{g}}=\right.$ 
$0.0 \mathrm{~cm}$ ), the critical flexural performance of the column $\mathrm{C} 16$ is evaluated even for values of Sa lower than $0.2 \mathrm{~g}$.

In Fig. 9, the fragility assessment of the inter-story pounding risk based on the local shear performances of the column $\mathrm{C} 16$ is presented. It can be observed that this column is in critical condition due to shear capacity demand when the initial gap distance between the adjacent structures is equal to $0.0 \mathrm{~cm}$ even for values of Sa less than $0.1 \mathrm{~g}$. In the case of considering a value of $\mathrm{Sa}=0.4 \mathrm{~g}$ the probability of exceeding the shear capacity $\mathrm{V}_{\mathrm{Rd}}$ is $46 \%$ and $9 \%$ for $\mathrm{d}_{\mathrm{g}}=4.5 \mathrm{~cm}$ and $\mathrm{d}_{\mathrm{g}}=9.0 \mathrm{~cm}$, respectively. On the other hand, the probability is zero when the 8 -story $\mathrm{RC}$ frame is vibrating freely.

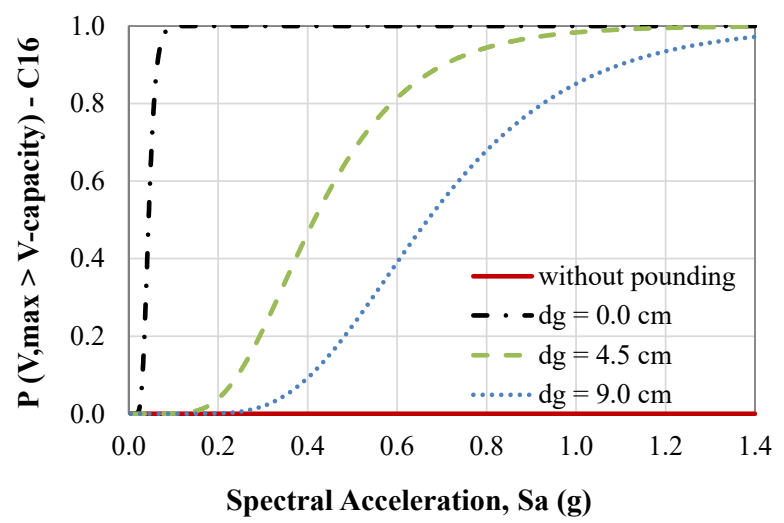

Figure 9: Fragility assessment of the critical column $\mathrm{C} 16$ of the 8-story RC frame against the inter-story pounding risk, in terms of $\mathrm{V}_{\max } \mid \mathrm{Sa}$, when $\mathrm{d}_{\mathrm{g}}=0.0 \mathrm{~cm}, \mathrm{~d}_{\mathrm{g}}=4.5 \mathrm{~cm}$, and $\mathrm{d}_{\mathrm{g}}=9.0 \mathrm{~cm}$.

\section{CONCLUSIONS}

Based on the results of this study the following concluding remarks are noted:

- The 8-story RC frame is more vulnerable on suffering the inter-story pounding from the adjacent 3 -story rigid structure, as smaller the initial separation distance $\left(\mathrm{d}_{\mathrm{g}}\right)$ between them is.

- The fragility curves are shifted to lower values of Sa due to the inter-story pounding effect in comparison to the corresponding cases without pounding. Nevertheless, the more exigent the performance level is the fragility curves move towards greater values of earthquake intensity.

- The probability of the 8-story RC frame to exceed a specific global or local performance level at the same value of intensity measure is increased due to the inter-story pounding effect.

- The local performances of the columns of the 8-story RC structure proved to be crucial demand parameters for the probabilistic assessment of the inter-story pounding risk. Thus, it can be stated that the local fragility curves in terms of flexural and shear capacity of the most crucial structural member should be incorporated on the evaluation of the seismic performance of structures against inter-story pounding risk. 
- Finally, PSDMs that are used for the fragility assessment of the inter-story pounding effect should be based on bilinear regression models in the case of evaluating the local EDPs, while global EDPs can be described based on linear PSDMs.

\section{REFERENCES}

[1] Anagnostopoulos, S.A. \& Spiliopoulos, K.V., An investigation of earthquake induced pounding between adjacent buildings. Earthquake Engineering and Structural Dynamics, 21, pp. 289-302, 1992.

[2] Karayannis, C.G. \& Favvata, M.J., Earthquake-induced interaction between adjacent reinforced concrete structures with non-equal heights. Earthquake Engineering and Structural Dynamics, 34, pp. 1-20, 2005.

[3] Karayannis, C.G. \& Favvata, M.J., Inter-story pounding between multistory reinforced concrete structures. Structural Engineering and Mechanics, 20(5), pp. 505-526, 2005.

[4] Jankowski, R., Assessment of damage due to earthquake-induced pounding between the main building and the stairway tower. Key Engineering Materials, 347, pp. 339344, 2007.

[5] Cole, G.L., Dhakal, R.P. \& Turner, F.M., Building pounding damage observed in the 2011 Christchurch earthquake. Earthquake Engineering and Structural Dynamics, 41(5), pp. 893-913, 2012.

[6] Abdel Raheem, S.E., Mitigation measures for earthquake induced pounding effects on seismic performance of adjacent buildings. Bulletin of Earthquake Engineering, 12(4), pp. 1705-1724, 2014.

[7] Favvata, M.J., Interaction of adjacent multistory RC frames at significant damage and near collapse limit states. WIT Transactions on the Built Environment, vol. 152, WIT Press: Southampton and Boston, pp. 47-59, 2015.

[8] Jankowski, R., Pounding between inelastic three-storey buildings under seismic excitations. Key Engineering Materials, 665, pp. 121-124, 2016.

[9] Favvata, M.J., Minimum required separation gap for adjacent RC frames with potential inter-story seismic pounding. Engineering Structures, 152, pp. 643-659, 2017.

[10] Abdel Raheem, S.E., Alazrak, T., Abdel Shafy, A., Ahmed, M. \& Gamal, Y., Seismic pounding between adjacent buildings considering soil-structure interaction. Engineering Structures, 20(1), pp. 55-70, 2021.

[11] Hong, H.P., Wang, S.S. \& Hong, P., Critical building separation distance in reducing pounding risk under earthquake excitation. Structural Safety, 25(3), pp. 287-303, 2003.

[12] Lin, J.H. \& Weng, C.C., Probability analysis of seismic pounding of adjacent buildings. Earthquake Engineering and Structural Dynamics, 30(10), pp. 1539-1557, 2001.

[13] Lopez-Garcia, D. \& Soong, T.T., Assessment of the separation necessary to prevent seismic pounding between linear structural systems. Probabilistic Engineering Mechanics, 24(2), pp. 210-223, 2009.

[14] Lopez-Garcia, D. \& Soong, T.T., Evaluation of current criteria in predicting the separation necessary to prevent seismic pounding between nonlinear hysteretic structural systems. Engineering Structures, 31(5), pp. 1217-1229, 2009.

[15] Tubaldi, E. \& Barbato, M., Stochastic analysis of the risk of seismic pounding between adjacent buildings. Computational Methods in Stochastic Dynamics, 26, pp. 309-326, 2013. 
[16] Tubaldi, E., Freddi, F. \& Barbato, M., Probabilistic seismic demand and fragility assessment for evaluating the separation distance between adjacent buildings. Proceedings of the 11th International Conference on Structural Safety and Reliability, New York, USA, pp. 1641-1648, 2013.

[17] Barbato, M. \& Tubaldi, E., A probabilistic performance-based approach for mitigating the seismic pounding risk between adjacent buildings. Earthquake Engineering and Structural Dynamics, 42(8), pp. 1203-1219, 2013.

[18] Wu Q., Yan H., Zhu H. \& Ding L., Probabilistic performance-based assessment for critical separation distance of adjacent buildings: Theoretical analysis. ASCE Journal of Performance of Constructed Facilities, 34(4), pp. 1-12, 2020.

[19] Chase, J.G., Boyer, F., Rodgers, G.W., Labrosse, G. \& MacRae, G.A., Probabilistic risk analysis of structural impact in seismic events for linear and nonlinear systems. Earthquake Engineering and Structural Dynamics, 43(10), pp. 1565-1580, 2014.

[20] Tubaldi, E., Freddi, F. \& Barbato, M., Probabilistic seismic demand model for pounding risk assessment. Earthquake Engineering and Structural Dynamics, 45(11), pp. 1743-1758, 2016.

[21] Naeej, M., Amiri, J.V. \& Jalali, S.G., Probabilistic evaluation of separation distance between two adjacent structures. Structural Engineering and Mechanics, 67(5), pp. 427-437, 2018

[22] Flegga, M.G. \& Favvata, M.J., Global and local performance levels on the probabilistic evaluation of the structural pounding effect between adjacent RC structures. Proceedings of the 11th International Conference on Structural Dynamics, EURODYN, vol. 2, Athens, Greece, pp. 3762-3779, 2020.

[23] Kazemi, F., Miari, M. \& Jankowski, R., Investigating the effects of structural pounding on the seismic performance of adjacent RC and steel MRFs. Bulletin of Earthquake Engineering, 19, pp. 317-343, 2021.

[24] Vamvatsikos, D. \& Cornell, C.A., Incremental dynamic analysis. Earthquake Engineering and Structural Dynamics, 31(3), pp. 491-514, 2002.

[25] Shome, N., Probabilistic seismic demand analysis of nonlinear structures. Report No. RMS-35, Department of Civil Engineering, Stanford University, 1999.

[26] Cornell, C.A., Jalayer, F., Hamburger, R.O. \& Foutch, D.A., Probabilistic basis for 2000 SAC federal emergency management agency steel moment frame guidelines. ASCE Journal of Structural Engineering, 128(4), pp. 526-533, 2002.

[27] Ramamoorthy, S.K., Gardoni, P. \& Bracci, J.M., Probabilistic demand models and fragility curves for reinforced concrete frames. ASCE Journal of Structural Engineering, 132(10), pp. 1563-1572, 2006.

[28] PEER ground motion database. 2011. http://peer.berkeley.edu/peer_ground_motion_ database.

[29] Applied Technology Council (ATC), Seismic evaluation and retrofit of concrete buildings, vols 1 and 2. Report No. ATC-40, Redwood City, CA, 1996.

[30] Eurocode 2, Design of concrete structures. Part 1: General rules and rules for buildings. EN 1992-1-1, European Committee for Standardization, Brussels, 2004.

[31] Eurocode 8, Design of structures for earthquake resistance. Part 1: General rules, seismic actions and rules for buildings. EN 1998-1, European Committee for Standardization, Brussels, 2004.

[32] Eurocode 8, Design of structures for earthquake resistance. Part 3: Assessment and retrofitting of buildings. EN 1998-3, European Committee for Standardization, Brussels, 2005. 